\title{
Estudo exploratório do uso da vinhaça ao longo do tempo. I. Características do solo
}

Cornélio A. Zolinn ${ }^{1}$, Janaina Paulino ${ }^{1}$, Altair Bertonha ${ }^{2}$, Paulo S. L. de Freitas ${ }^{2} \&$ Marcos V. Folegatti $^{1}$

\section{RESUMO}

O bjetivou-se, neste trabalho, a realização de um estudo exploratório da aplicação de vinhaça, ao longo dos anos, nas propriedades dos solos com cana-de-açúcar, através de uma análise comparativa e sistemática. $O$ presente trabalho foi desenvolvido na empresa USACIGA - Açúcar, Álcool e Energia Elétrica S.A. localizada em Cidade Gaúcha, região noroeste do estado do Paraná cujos tratamentos foram constituídos de áreas cultivadas com cana-de-açúcar e submetidas a diferentes tempos de aplicação de vinhaça, respectivamente 1, 2, 3, 4, 12 e 20 anos, e uma área Testemunha, sem aplicação. Em todas as áreas estudadas foram abertas trincheiras de $1 \mathrm{~m}^{3}$, georreferenciadas em $340 \mathrm{~m}$ de altitude para realização da classificação dos solos e coleta de amostras. Realizaram-se avaliações da densidade do solo, densidade de partícula, teor de carbono orgânico, Capacidade de Troca Catiônica (CTC), porosidade total, armazenamento e disponibilidade de água para a cultura de cana-de-açúcar, além das relações entre $\mathrm{K}, \mathrm{Ca}, \mathrm{Mg}$ e $\mathrm{V} \%$. O s resultados indicaram que a aplicação de vinhaça contribuiu para o aumento dos teores de carbono orgânico e potássio do solo e que a produtividade da cultura da cana-de-açúcar apresentou uma relação direta ao aumento da razão de adsorção de potássio no solo.

Palavras-chave: fertirrigação, produtividade da cana-de-açúcar, armazenamento de água

\section{Exploratory study of the stillage use along the time. I. Characteristics of the soil}

\begin{abstract}
The aim of this study was to accomplish an exploratory study of the stillage in the areas with sugarcane, through a comparative and systematic analysis. The present work was conducted in the company USACIG A - Sugar, Alcohol and Electric Power S.A. located at G aúcha, northwest Paraná state. Treatments constituted of areas cultivated with sugarcane and submitted to different times of stillage application, respectively $1,2,3,4,12$ and 20 years, and a reference area, without application. In all the studied areas trenches of $1 \mathrm{~m}^{3}$ were opened, geo referenced in $340 \mathrm{~m}$ of altitude for accomplishment of the soil classification and sample collection. The evaluations were performed of the density, soil particle density, organic carbon, cation exchange capacity (CEC), total porosity, soil water moisture for the sugarcane, besides the relationships among $\mathrm{K}, \mathrm{Ca}, \mathrm{Mg}$ and $\mathrm{V} \%$. The results indicated that the stillage application contributed to the organic carbon and potassium increase in the soil and that the sugarcane productivity presented a direct relationship with the ratio of potassium adsorption increase in the soil.
\end{abstract}

Key words: fertigation, sugarcane productivity, water storage 


\section{INTRODUÇÃO}

O estado do Paraná é o segundo maior produtor de canade-açúcar do País, ficando atrás somente do estado de São Paulo e o seu cultivo acontece principalmente na região noroeste do estado, onde se concentra a maior parte das agroindústrias sucroalcoleiras (Silva et al., 2010).

$\mathrm{Na}$ região noroeste do Estado do Paraná os solos são originados do Arenito Caiuá, possuem entre 80 e $90 \%$ de areia e são classificados, em sua maior parte, como Latossolos, os quais apresentam propriedades físicas favoráveis à exploração agrícola, apesar da baixa fertilidade natural (Sambatti et al., 2003).

O setor sucroalcooleiro é um dos setores que melhor uso fazem dos efluentes gerados e isto não se dá apenas devido à crescente consciência ambiental mas, sobretudo, porque os efluentes produzidos têm grande quantidade de nutrientes (Silva et al., 2005) e não possuem metais pesados, nem sódio e alumínio em sua composição. Ainda segundo estes autores o constituinte principal da vinhaça é a matéria orgânica sob forma de ácidos orgânicos em menor quantidade, por cátion como K, $\mathrm{Ca}$ e $\mathrm{Mg}$.

As mudanças nas propriedades químicas do solo, elevação do $\mathrm{pH}$, aumento da disponibilidade de nutrientes e aumento da capacidade de troca catiônica, promovidas pela aplicação da vinhaça, conforme descrevem Glória \& Orlando Filho (1983), podem alterar a estabilidade de agregados, a dispersão de argila e a densidade do solo (Silva, 2006; Camilotti et al., 2006; 2009; Bebé et al., 2009); também, as adições de resíduos orgânicos podem resultar no incremento do teor de matéria orgânica, alterando seus atributos físicos, como a agregação de partículas (Canellas et al., 2003).

Estudos desenvolvidos por Camargo et al. (1983) e Andrioli (1986) mostraram que a aplicação de vinhaça não altera a densidade, a porosidade total, a macroporosidade nem a microporosidade do solo, devido ao fato de não ocorrer aumento de matéria orgânica do solo, fato contestado com o trabalho de Canellas et al. (2003) que relataram aumento do teor de matéria orgânica e, com isto, melhoria nas condições físicas do solo em virtude de aplicações de vinhaça ao longo dos anos.

Casarini et al. (1985) e Camilotti et al. (2006) afirmam que os efeitos da aplicação de vinhaça são passageiros. Andrioli (1986) estudando os atributos físicos de um latossolo cultivado com cana-de-açúcar após aplicações de $1200 \mathrm{~m}^{3} \mathrm{ha}^{-}$ ${ }^{1}$ de vinhaça, verificou que não houve alteração no teor de matéria orgânica nem porosidade total; já Canellas et al. (2003) constataram que um Cambissolo cultivado com cana-deaçúcar teve aumento de carbono orgânico depois 35 anos de aplicação de vinhaça.

Devido à expansão das áreas cultivadas com cana-de-açúcar no noroeste do Paraná e consequente aumento da produção de efluentes, fazem-se necessários trabalhos que analisem as modificações que a aplicação deste efluente pode ocasionar no solo, e qual o reflexo disto na produtividade da cana-deaçúcar.

Neste contexto, realizou-se o presente trabalho com o objetivo de realizar um estudo exploratório da aplicação de vinhaça, ao longo dos anos, nas propriedades dos solos cultivados com cana-de-açúcar, empregando-se uma análise comparativa e sistemática dos dados levantados.

\section{Material E MÉTODOS}

O presente trabalho foi realizado em Cidade Gaúcha, região noroeste do Paraná. O clima da região é subtropical úmido mesotérmico, conforme a classificação de Köppen.

Os tratamentos constaram de áreas de cultivo de cana-deaçúcar que receberam aplicação de vinhaça durante 1, 2, 3, 4, 12 e 20 anos, respectivamente, e uma área testemunha sem aplicação. Para as áreas que receberam vinhaça, cada ano corresponde a uma aplicação de $150 \mathrm{~m}^{3} \mathrm{ha}^{-1}$ efetuada por um canhão autopropelido com taxa de aplicação média de $12,5 \mathrm{~mm} \mathrm{~h}^{-1}$.

Para a coleta das amostras e classificação dos solos, trincheiras de $1 \mathrm{~m}^{3}$ foram abertas em cada área estudada, distanciadas $100 \mathrm{~m}$ do carreador onde ocorre o tráfego das máquinas e a classificação dos solos foi realizada de acordo com o Sistema Brasileiro de Classificação de Solos (EMBRAPA, 1999). A classificação dos solos das áreas estudadas está discriminada na Tabela 1 .

Tabela 1. Número de aplicações de vinhaça, altitude do local, classificação do solo e cultivar de cana de açúcar

\begin{tabular}{|c|c|c|c|}
\hline $\begin{array}{l}\text { Número de } \\
\text { aplicações } \\
\text { de vinhaça }\end{array}$ & $\begin{array}{l}\text { Altitude } \\
\text { (m) }\end{array}$ & Classificação do solo & Variedade \\
\hline Testemunha & 340,00 & Latossolo Vermelho Distrófico & RB 855156 \\
\hline 1 Aplicação & 340,73 & Argissolo Vermelho Distrófico & RB 845239 \\
\hline 2 Aplicações & 340,76 & Latossolo Vermelho Distrófico & RB 855536 \\
\hline 3 Aplicações & 338,40 & Latossolo Vermelho Distrófico & RB $72-454$ \\
\hline 4 Aplicações & 339,94 & Latossolo Vermelho Distrófico & RB $72-454$ \\
\hline 12 Aplicações & 340,42 & Latossolo Vermelho Distrófico & RB 835486 \\
\hline 20 Aplicações & 340,90 & Latossolo Vermelho Distrófico & RB $72-454$ \\
\hline
\end{tabular}

A composição química média da vinhaça citada por Silva (2006) está apresentada na Tabela 2.

Tabela 2. Composição química média da vinhaça

\begin{tabular}{|c|c|c|c|c|c|c|c|c|c|}
\hline \multirow{2}{*}{ pH } & \multirow{2}{*}{$\begin{array}{c}\mathrm{CE}^{*} \\
\mathrm{dS} \mathrm{m}^{-1}\end{array}$} & C & $\mathbf{N}$ & $\mathrm{P}_{2} \mathrm{O}_{5}$ & $\mathrm{~K}_{2} \mathrm{O}$ & $\mathrm{Ca}^{2+}$ & $\mathrm{Mg}^{2+}$ & $\mathrm{SO}_{4}{ }^{2-}$ & \multirow{2}{*}{$\begin{array}{l}\mathrm{Fe}^{2+} \\
\mathrm{mg} \mathrm{L}^{-1}\end{array}$} \\
\hline & & \multicolumn{7}{|c|}{$\mathrm{g} \mathrm{L}^{-1}$} & \\
\hline 5,71 & 3,60 & 9,3 & 0,56 & 0,19 & 0,96 & 0,28 & 0,13 & 3,11 & 1,14 \\
\hline
\end{tabular}

As análises granulométrica e química dos solos estão apresentadas nas Tabelas 3 e 4, respectivamente. As amostras foram coletadas a $0,10 \mathrm{~m}$, representando a profundidade de 0 a $0,20 \mathrm{~m}$, e a $0,30 \mathrm{~m}$, representando a profundidade de 0,20 a 0,40 $\mathrm{m}$, procurando representar a profundidade efetiva do sistema radicular da cana-de-açúcar.

As avaliações da densidade do solo, densidade de partículas e porosidade total, foram realizadas nas profundidades de $0-0,15,0,15-0,30$ e $0,30-0,50 \mathrm{~m}$, de acordo com a metodologia proposta por Reichardt \& Timm (2008).

Para a determinação da disponibilidade de água no solo retiraram-se três amostras indeformadas de cada uma das 
Tabela 3. Análise granulométrica dos solos

\begin{tabular}{cccccc}
\hline Tratamento & $\begin{array}{c}\text { Profundidade } \\
(\mathbf{m})\end{array}$ & $\begin{array}{c}\text { Areia } \\
\text { grossa }\end{array}$ & $\begin{array}{c}\text { Areia } \\
\text { fina }\end{array}$ & Silte & Argila \\
\cline { 3 - 6 } & & \multicolumn{4}{c}{$\%$} \\
Testemunha & $0-0,20$ & 26 & 66 & 3 & 5 \\
Testemunha & $0-0,40$ & 25 & 67 & 2 & 6 \\
1 aplicação & $0-0,20$ & 48 & 43 & 3 & 6 \\
1 aplicação & $0-0,40$ & 41 & 46 & 3 & 10 \\
2 aplicações & $0-0,20$ & 35 & 59 & 2 & 4 \\
2 apliçções & $0-0,40$ & 30 & 62 & 3 & 5 \\
3 aplicações & $0-0,20$ & 45 & 48 & 2 & 5 \\
3 aplicações & $0-0,40$ & 44 & 46 & 4 & 6 \\
4 aplicações & $0-0,20$ & 35 & 55 & 4 & 6 \\
4 aplicações & $0-0,40$ & 34 & 57 & 3 & 6 \\
12 aplicações & $0-0,20$ & 51 & 43 & 2 & 4 \\
12 aplicações & $0-0,40$ & 52 & 39 & 3 & 6 \\
20 aplicações & $0-0,20$ & 42 & 44 & 2 & 12 \\
20 aplicações & $0-0,40$ & 34 & 48 & 2 & 16 \\
\hline
\end{tabular}

seguintes profundidades: 0-0,20 e 0,20-0,50 m do perfil das trincheiras, as quais foram protegidas com "papel alumínio", acondicionadas em caixa térmica e em seguida encaminhadas ao Laboratório de Análises de Solos.

Determinou-se a curva de retenção de água obtendo-se o volume de água no solo para os potenciais de 1, 2, 4, 6, 8, 50 e $1500 \mathrm{kPa}$, com os quais foi ajustado o modelo de van Genuchten, com uso do programa Soil Water Retention Curve - SWRC (Dourado Neto et al., 2000).

A quantidade de água disponível para as plantas nas camadas de 0-0,20 e 0,20-0,50 m de profundidade foi estimada pela diferença entre a umidade volumétrica do solo submetida ao potencial mátrico de 50 e $600 \mathrm{kPa}$.

Os dados de produtividade média foram obtidos junto à USACIGA - Açúcar, Álcool e Energia Elétrica S.A., com exceção da área Testemunha, que ainda não havia sido colhida.

\section{RESULTADOS E DISCUSSÃO}

Observa-se, na Figura 1, que todas as áreas apresentaram os maiores valores de densidade do solo na camada de 0,15 a 0,30 m, com exceção da área que recebeu aplicação de vinhaça durante 12 anos, que apresentou o maior valor de densidade na camada superficial do solo $(0-0,15 \mathrm{~m})$. Observou-se, no campo, uma camada de solo visivelmente compactada nesta área com 12 anos de aplicação o que pode explicar o maior valor de densidade nas camadas, uma vez que, segundo Camargo \& Alleoni (2006), a densidade do solo é a medida quantitativa mais direta da compactação.

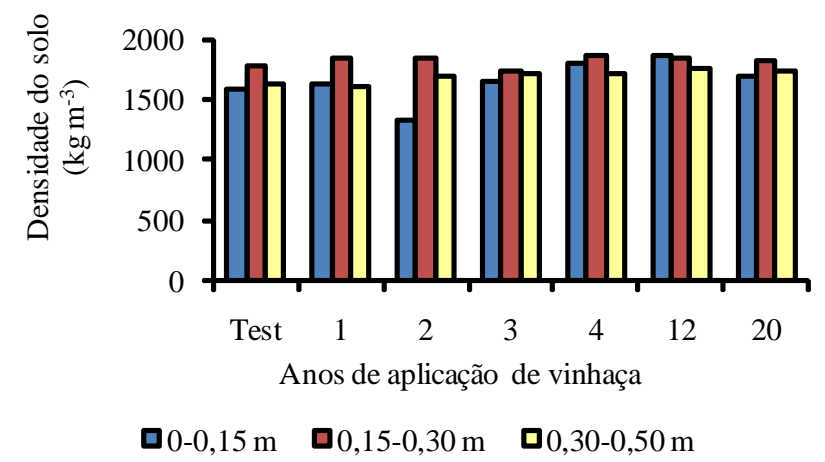

Figura 1. Densidade do solo para as áreas estudadas

Na Figura 2A está apresentada a densidade de partícula para as áreas estudadas; observa-se que os maiores valores foram encontrados na profundidade de 0,30 a $0,50 \mathrm{~m}$ para as áreas, a partir do segundo ano de aplicação; para a camada de 0,15 a $0,30 \mathrm{~m}$, houve tendência de diminuição da densidade de partícula ao longo dos anos de aplicação de vinhaça, novamente com exceção da área com 12 anos devido aos indícios de compactação.

Analisando os teores de carbono orgânico e a densidade do solo é possível verificar uma relação direta entre ambos, ou seja, maiores valores de carbono orgânico implicaram em menores valores de densidade, que podem ser facilmente visualizados, principalmente na camada superficial 0-0,15 m. Braida et al. (2006) estudaram a compactação dos solos na camada de 0 a $0,05 \mathrm{~m}$ e encontraram menor densidade onde se tinha acúmulo de matéria orgânica, e Boeira et al. (2007) trabalhando com aplicação de lodo de esgoto no solo, notaram diminuição da densidade e aumento do estoque de carbono orgânico no solo até a profundidade de $0,40 \mathrm{~m}$.

Tabela 4. Análise química do solo na camada de 0 a $0,40 \mathrm{~m}$

\begin{tabular}{|c|c|c|c|c|c|c|c|c|c|c|c|c|c|c|c|}
\hline \multirow{2}{*}{ Tratamento } & \multicolumn{2}{|c|}{$\mathrm{pH}$} & $\mathrm{Al}^{3+}$ & $\mathrm{H}^{+}+\mathrm{Al}^{3+}$ & $\mathrm{Ca}^{2+}$ & $\mathrm{Mg}^{2+}$ & $\mathbf{K}^{+}$ & SB & CTC & \multirow{2}{*}{$\begin{array}{c}P \\
\mathrm{mg} \mathrm{dm}^{-3}\end{array}$} & \multirow{2}{*}{$\begin{array}{c}C \\
\mathrm{~g} \mathrm{dm}^{-3}\end{array}$} & $\mathrm{Ca}$ & $\mathrm{Mg}$ & K & m \\
\hline & $\mathrm{CaCl}_{2}$ & $\mathrm{H}_{2} \mathrm{O}$ & & & & $\mathrm{ol}_{\mathrm{c}} \mathrm{dm}^{-}$ & & & & & & \multicolumn{4}{|c|}{$\%$} \\
\hline Test. $0-20$ & 6,1 & 7,0 & 0 & 1,61 & 1,55 & 0,32 & 0,06 & 1,93 & 3,54 & 20,4 & 3,56 & 43,79 & 9,04 & 1,69 & 0 \\
\hline Test. 20-40 & 5,9 & 7,0 & 0 & 1,61 & 0,98 & 0,29 & 0,04 & 1,31 & 2,92 & 9,4 & 2,37 & 33,56 & 9,93 & 1,37 & 0 \\
\hline 1 aplic. 0-20 & 4,8 & 5,7 & 0 & 2,73 & 1,15 & 0,35 & 0,11 & 1,61 & 4,34 & 10,1 & 6,72 & 26,50 & 8,06 & 2,53 & 0 \\
\hline 1 aplic. 20-40 & 5,1 & 6,1 & 0 & 2,03 & 1,02 & 0,31 & 0,04 & 1,37 & 3,40 & 2,1 & 4,35 & 30,00 & 9,12 & 1,18 & 0 \\
\hline 2 aplic. $0-20$ & 6,2 & 7,1 & 0 & 1,74 & 2,42 & 0,30 & 0,14 & 2,86 & 4,60 & 98,4 & 6,72 & 52,61 & 6,52 & 3,04 & 0 \\
\hline 2 aplic. $20-40$ & 6,3 & 7,3 & 0 & 1,61 & 1,59 & 0,25 & 0,17 & 2,01 & 3,62 & 40,1 & 3,16 & 43,92 & 6,91 & 4,70 & 0 \\
\hline 3 aplic. 0-20 & 5,6 & 6,6 & 0 & 1,88 & 1,78 & 0,55 & 0,24 & 2,57 & 4,45 & 48,6 & 6,32 & 40,00 & 12,36 & 5,39 & 0 \\
\hline 3 aplic. 20-40 & 5,8 & 7,0 & 0 & 1,74 & 1,14 & 0,35 & 0,24 & 1,73 & 3,47 & 9,9 & 2,77 & 32,85 & 10,09 & 6,92 & 0 \\
\hline 4 aplic. 0-20 & 5,0 & 6,1 & 0 & 2,36 & 1,21 & 0,44 & 0,15 & 1,80 & 4,16 & 10,4 & 6,32 & 29,09 & 10,58 & 3,61 & 0 \\
\hline 4 aplic. $20-40$ & 4,8 & 6,2 & 0 & 1,88 & 0,67 & 0,23 & 0,11 & 1,01 & 2,89 & 4,4 & 2,77 & 23,18 & 7,96 & 3,81 & 0 \\
\hline 12 aplic. 0-20 & 5,0 & 6,3 & 0 & 2,19 & 0,89 & 0,36 & 0,22 & 1,47 & 3,66 & 12,2 & 4,74 & 24,32 & 9,84 & 6,01 & 0 \\
\hline 12 aplic. $20-40$ & 5,0 & 6,3 & 0 & 2,03 & 1,12 & 0,25 & 0,17 & 1,54 & 3,57 & 4,6 & 3,56 & 31,37 & 7,00 & 4,76 & 0 \\
\hline 20 aplic. 0-20 & 4,2 & 5,3 & 0,2 & 3,42 & 0,66 & 0,31 & 0,19 & 1,16 & 4,58 & 70,4 & 8,69 & 14,41 & 6,77 & 4,15 & 14,7 \\
\hline 20 aplic. $20-40$ & 4,3 & 5,1 & 0,2 & 2,73 & 0,68 & 0,3 & 0,09 & 1,07 & 3,80 & 15,4 & 5,14 & 17,89 & 7,89 & 2,37 & 15,8 \\
\hline
\end{tabular}

$\mathrm{Ca}, \mathrm{Mg}, \mathrm{Al}$ - extraídos com KCl $1 \mathrm{~mol} \mathrm{~L}^{-1} ; \mathrm{P}, \mathrm{K}$ - extraídos com Mehlich 1; H+ Al- método SMP; C - método Walkley \& Black 


\section{A.}

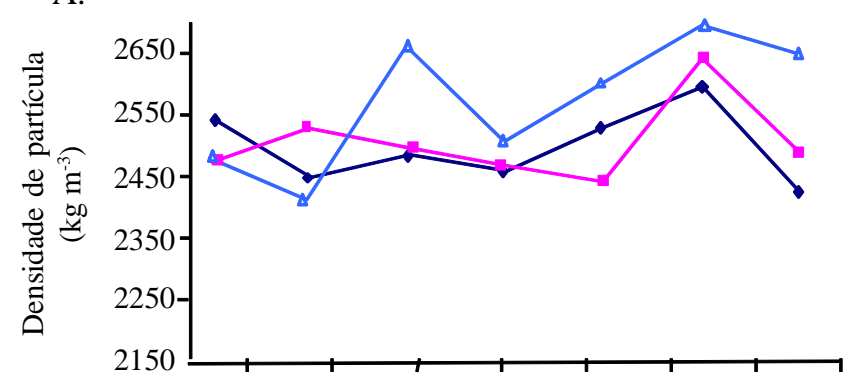

B.

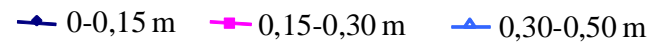

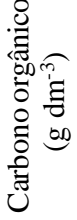

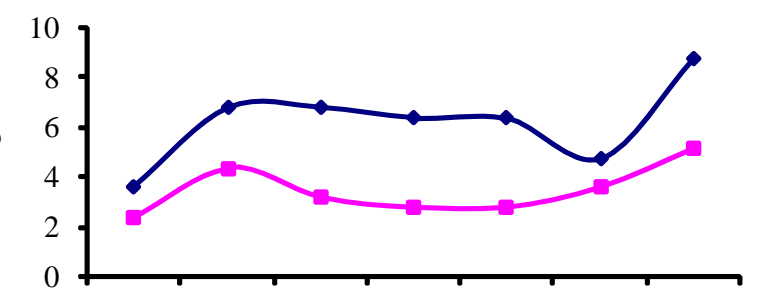

C.
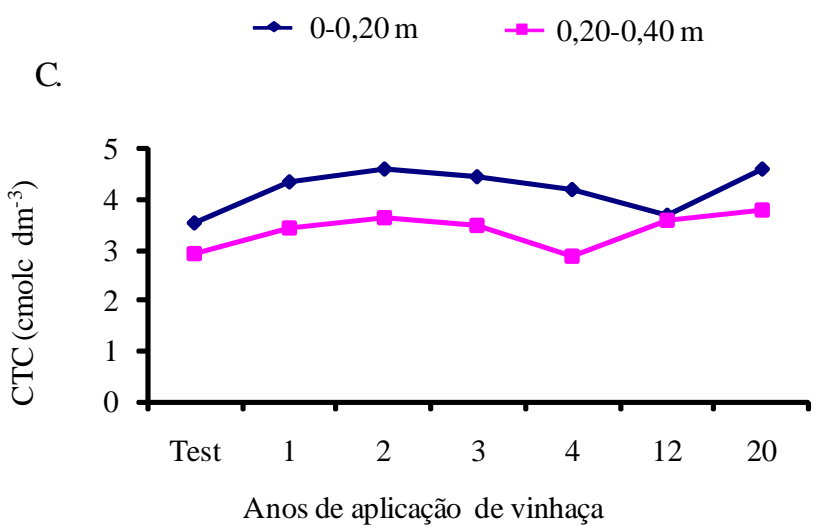

$\rightarrow 0-0,20 \mathrm{~m} \quad-0,20-0,40 \mathrm{~m}$

Figura 2. D ensidade de partícula (A), Teores de carbono orgânico (B) e Capacidade de troca catiônica para as áreas estudadas (C)

Analisando os dados referentes aos Latossolos (Testemunha, 2, 3, 4, 12 e 20 anos de aplicação de vinhaça), nota-se que, já a partir da primeira aplicação de vinhaça, os teores de carbono orgânico (Figura 2B) tenderam a aumentar com o tempo de aplicação de vinhaça, corroborando com Canellas et al. (2003) que perceberam alterações químicas e melhoria na fertilidade e qualidade da matéria orgânica no solo com a adição de matéria orgânica na lavoura de cana-de-açúcar, por longo prazo.

Camilotti et al. (2006) não constataram alteração no teor de matéria orgânica do solo, em contraste com Canellas et al. (2003); o autor sugere que a matéria orgânica do solo pode aumentar após sucessivas aplicações por um período de tempo maior do que o considerado em seu trabalho (quatro anos). Na Figura 2B é possível visualizar que os teores de carbono orgânico encontrados até o quarto ano se mantiveram semelhantes e a partir dos 12 anos nota-se um acréscimo, sendo a área com 20 anos a que apresentou os maiores valores.

Na Figura 2C, está apresentada a CTC do solo nas camadas de 0-0,20 e 0,20-0,40 m para todas as áreas estudadas. Verificase que a CTC foi maior na camada superficial do solo $(0-0,15 \mathrm{~m})$ mantendo-se com pequenas variações ao longo dos anos de aplicação de vinhaça. Nota-se que a CTC do solo apresenta uma relação diretamente proporcional aos teores de carbono orgânico e que os teores de carbono orgânico são mais expressivos na camada superficial do solo, como observado por Ciotta et al. (2003).

Na Tabela 5 se apresentam os valores de porosidade total na qual se pode observar que a porosidade do solo aumentou a medida em que a quantidade de carbono orgânico presente no solo aumentava, sendo mais clara esta relação na camada superficial de 0 a $0,15 \mathrm{~m}$; resultados semelhantes foram observados por Marciano et al. (2001).

Tabela 5. Porosidade total (\%) em três profundidades, em função do tempo de aplicação de vinhaça no solo

\begin{tabular}{cccccccc}
\hline $\begin{array}{c}\text { Profundidade } \\
\text { (m) }\end{array}$ & Testemunha & \multicolumn{6}{c}{ Anos de aplicação de vinhaça } \\
\cline { 3 - 8 } & & $\mathbf{1}$ & $\mathbf{2}$ & $\mathbf{3}$ & $\mathbf{4}$ & $\mathbf{1 2}$ & $\mathbf{2 0}$ \\
$0-0,15$ & 37,1 & 33,5 & 46,0 & 32,3 & 28,5 & 27,6 & 29,8 \\
$0,15-0,30$ & 27,5 & 27,1 & 26,3 & 29,1 & 23,8 & 30,2 & 26,9 \\
$0,30-0,50$ & 34,6 & 33,5 & 36,2 & 31,4 & 33,8 & 34,3 & 34,3 \\
\hline
\end{tabular}

Tem-se, nas Figuras 3A e 3B, as curvas características da água no solo nas camadas de 0-0,20 e 0,20-0,50 m, respectivamente. Observa-se, na Figura 3A, que para as áreas Testemunha, 1, 2, 4, 12 e 20 anos de aplicação de vinhaça, após $600 \mathrm{kPa}$ de tensão, a inclinação das curvas se torna muito pequena, o que implica em valores praticamente constantes de umidade volumétrica sendo, a partir de então, quase insignificante a água disponível para as plantas.

Verifica-se, na Figura 3B, que as áreas Testemunha e 2 anos de aplicação de vinhaça apresentaram água disponível até uma tensão de $250 \mathrm{kPa}$, como verificado na área com 3 anos de aplicação de vinhaça na camada de 0-0,20 m; nas demais áreas observa-se uma disponibilidade de água mais expressiva, até $600 \mathrm{kPa}$.

Na Tabela 6 são apresentados os valores de armazenamento de água nas camadas de $0-0,20$ e $0,20-0,50 \mathrm{~m}$, referentes à diferença da umidade volumétrica no intervalo entre 50 e 600 $\mathrm{kPa}$, considerando-se este intervalo referente à água disponível para as plantas, nesta situação.

Valores extremos de armazenamento de água foram encontrados na camada de 0-0,20 m nas áreas com 1 e 12 anos de aplicação e na camada de 0,20-0,50 m nas áreas Testemunha e 4 anos de aplicação de vinhaça. Percebe-se grande variação no armazenamento de água para as áreas estudadas; Silva et al. (2005) atribuem esta variação à modificação da distribuição de diâmetro de poros dos solos.

Considerando-se como armazenamento total de água disponível para cultura a diferença da umidade volumétrica referente às tensões de 50 e $1000 \mathrm{kPa}$, pode-se verificar que mais de $83 \%$ do armazenamento se concentraram até a tensão 


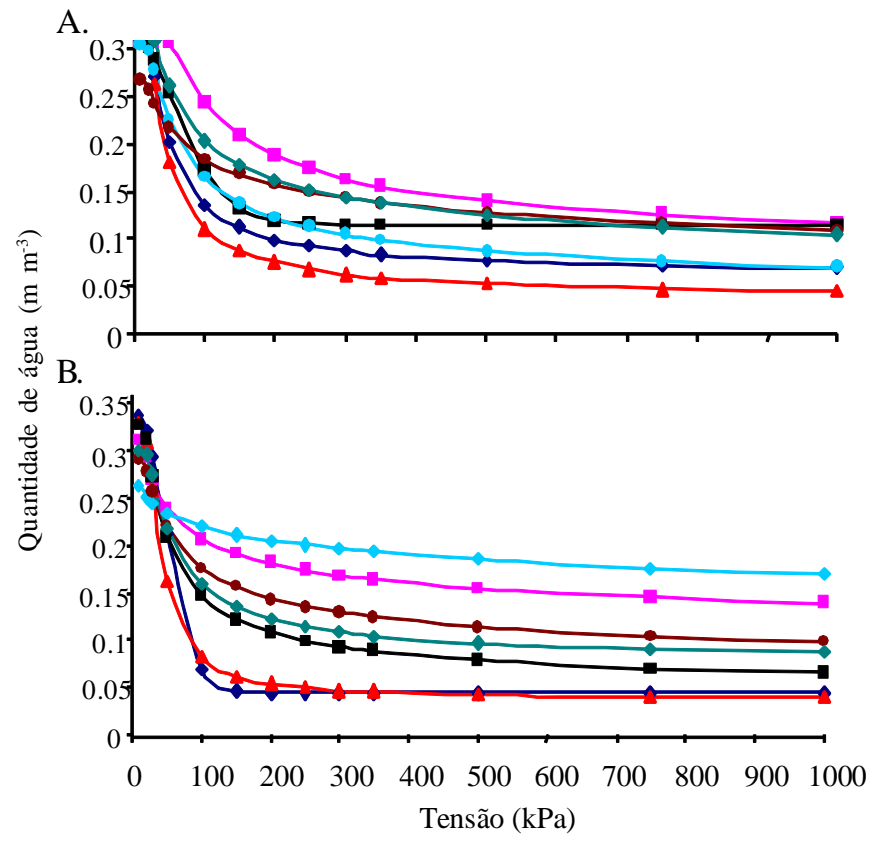

$\rightarrow$ Testemunha $\_1$ Aplicação $\rightarrow 2$ Aplicações $\rightarrow 3$ Aplicações $\rightarrow 4$ Aplicações $\rightarrow$ 12 Aplicações $\rightarrow$-20 Aplicações

Figura 3. Curva característica da água no solo para a camada de 0-0,20 m (A) e para a camada de 0,20-0,50 m (B)

Tabela 6. Armazenamento de água $(\mathrm{mm})$ nas camadas de $0-0,20$ e $0,20-0,50 \mathrm{~m}$

\begin{tabular}{cccccccc}
\hline $\begin{array}{c}\text { Profundidade } \\
\text { (m) }\end{array}$ & \multirow{2}{*}{ Testemunha } & \multicolumn{6}{c}{ Anos de aplicação de vinhaça } \\
\cline { 3 - 8 } & & $\mathbf{1}$ & $\mathbf{2}$ & $\mathbf{3}$ & $\mathbf{4}$ & $\mathbf{1 2}$ & $\mathbf{2 0}$ \\
$0-0,20$ & 25,4 & 34,7 & 26,0 & 27,9 & 28,8 & 18,9 & 28,7 \\
$0,20-0,50$ & 60,7 & 26,7 & 36,3 & 40,4 & 18,9 & 33,5 & 37,6 \\
Total & 86,1 & 61,4 & 62,3 & 68,3 & 47,7 & 52,4 & 66,3 \\
\hline
\end{tabular}

de $600 \mathrm{kPa}$, caracterizando-se como o intervalo mais importante para o estudo da disponibilidade de água para as plantas, nas classes de solo estudadas e que, a partir de então, o armazenamento representa uma pequena porcentagem do armazenamento total, como pode ser observado na Tabela 7.

Tabela 7. Porcentagem do armazenamento de água referente às tensões entre 600 e $1000 \mathrm{kPa}$

\begin{tabular}{cccccccc}
\hline Profundidade & \multirow{2}{*}{$(\mathbf{m})$} & Testemunha & \multicolumn{7}{c}{ Anos de aplicação de vinhaça } \\
\cline { 3 - 8 } & & $\mathbf{1}$ & $\mathbf{2}$ & $\mathbf{3}$ & $\mathbf{4}$ & $\mathbf{1 2}$ & $\mathbf{2 0}$ \\
$0-0,20$ & 3,9 & 8,4 & 3,9 & 0 & 7,6 & 12,7 & 8,5 \\
$0,20-0,50$ & 0 & 10,7 & 1,3 & 6,3 & 17,7 & 8,9 & 5,3 \\
\hline
\end{tabular}

Em se tratando de nutrientes no solo, Vitti \& Mazza (1998) informam que a relação $\mathrm{K}: \mathrm{Mg}: \mathrm{Ca}$ ideal para promover um equilíbrio entre os nutrientes no solo para a cultura da canade-açúcar, é de aproximadamente 1:3:9 a 1:5:25 com saturação por bases (V\%) em torno de 60\%. A relação K:Mg:Ca e V\% das áreas estudadas encontra-se na Tabela 8.

Na camada de 0 a 0,20 m as áreas Testemunha, 1 e 4 anos de aplicação, apresentaram valores da relação $\mathrm{K}: \mathrm{Mg}$ :Ca próximos do recomendado; nas demais áreas os valores encontrados foram abaixo da recomendação de Vitti \& Mazza (1998). Para a
Tabela 8. Relação K:M g:Ca e saturação por bases dos solos avaliados

\begin{tabular}{lccccccc}
\hline \multicolumn{1}{c}{$\begin{array}{c}\text { Relação } \\
\text { Prof. }(\mathbf{c m})\end{array}$} & \multirow{2}{*}{ Test. } & \multicolumn{6}{c}{ Anos de aplicação de vinhaça } \\
\cline { 3 - 8 } K:Mg:Ca & & $\mathbf{1}$ & $\mathbf{2}$ & $\mathbf{3}$ & $\mathbf{4}$ & $\mathbf{1 2}$ & $\mathbf{2 0}$ \\
- 0-0,20 & $1: 5: 26$ & $1: 3: 10$ & $1: 2: 17$ & $1: 2: 7$ & $1: 3: 8$ & $1: 2: 4$ & $1: 2: 3$ \\
K:Mg:Ca & & & & & & & \\
$-0,20-0,40$ & $1: 7: 25$ & $1: 8: 26$ & $1: 1: 9$ & $1: 1: 5$ & $1: 2: 6$ & $1: 1: 7$ & $1: 3: 8$ \\
V\%- 0/0,20 & 55 & 37 & 62 & 58 & 43 & 40 & 25 \\
V\%- $0,20 / 0,40$ & 45 & 40 & 56 & 50 & 35 & 43 & 28 \\
\hline
\end{tabular}

camada de 0,20 a 0,40 $\mathrm{m}$ as áreas Testemunha e 1 ano, apresentaram valores de $\mathrm{Mg}$ um pouco acima desta recomendação e a área com 20 anos apresentou valores bem próximos do indicado. Tratando-se da saturação por bases, a área Testemunha, na camada superficial, e as áreas com dois e três anos em ambas as profundidades, foram as áreas que apresentaram os valores mais altos e mais próximos de $60 \%$. Portanto, fazendo uma avaliação quanto aos valores propostos por Vitti \& Mazza (1998), a área que nunca recebeu aplicação de vinhaça apresentou os valores da relação K:Mg:Ca e V\% mais próximos do considerado ideal para a cultura da cana-deaçúcar.

Vitti \& Mazza (1998) informam, ainda, que uma relação Ca/ Mg em torno de 3 a 5:1, ajuda a manter o equilíbrio no solo quando já se tem condições ideais de V\% e da relação K:Mg:Ca. Nas Figuras 4A e 4B se acham os valores das relações $\mathrm{Ca} / \mathrm{Mg}$ e $\mathrm{K} /(\mathrm{Ca}+\mathrm{Mg})^{1 / 2}$ nas camadas de 0 a 0,20 e 0,20 a $0,40 \mathrm{~m}$.

Pode-se observar, na Figura 4A, que a maioria dos valores corresponde à relação indicada por Vitti \& Mazza (1998); apenas a área com 2 anos de aplicação de vinhaça apresentou valor superior e a área com 20 anos, valor inferior ao recomendado.

$\mathrm{Na}$ Figura 4B é possível observar aumento da razão de adsorção de potássio no solo até o terceiro ano de aplicação de vinhaça; após isto, nota-se uma redução nesses valores, com destaque para a área de 4 anos de aplicação de vinhaça, que apresentou o menor valor.

Na Figura 4C está apresentada a produtividade da cana-deaçúcar para todas as áreas estudadas, com exceção da área Testemunha. Observa-se um aumento da produtividade da cultura até o terceiro ano de aplicação de vinhaça e decréscimo dos 12 aos 20 anos de aplicação, visualizando o menor valor de produtividade na área com 4 anos de aplicação de vinhaça.

Quando se confronta a razão de adsorção de potássio K/ $(\mathrm{Ca}+\mathrm{Mg})^{1 / 2}$ com a produtividade da cana-de-açúcar, verificase uma relação sistemática entre esta razão e a produtividade, ou seja, houve um acréscimo da produtividade da cultura da cana-de-açúcar com o aumento da razão de adsorção de potássio no solo; Rossetto et al. (2004) também relacionaram o aumento da produtividade da cana-de-açúcar com o aumento do Potássio no solo.

Outra observação interessante a respeito do potássio é que, nos solos correspondentes às áreas com aplicação de vinhaça e independente dos períodos de aplicação, houve um aumento deste nutriente nas duas profundidades avaliadas, corroborando com os resultados encontrados por Bebé et al. (2009). 

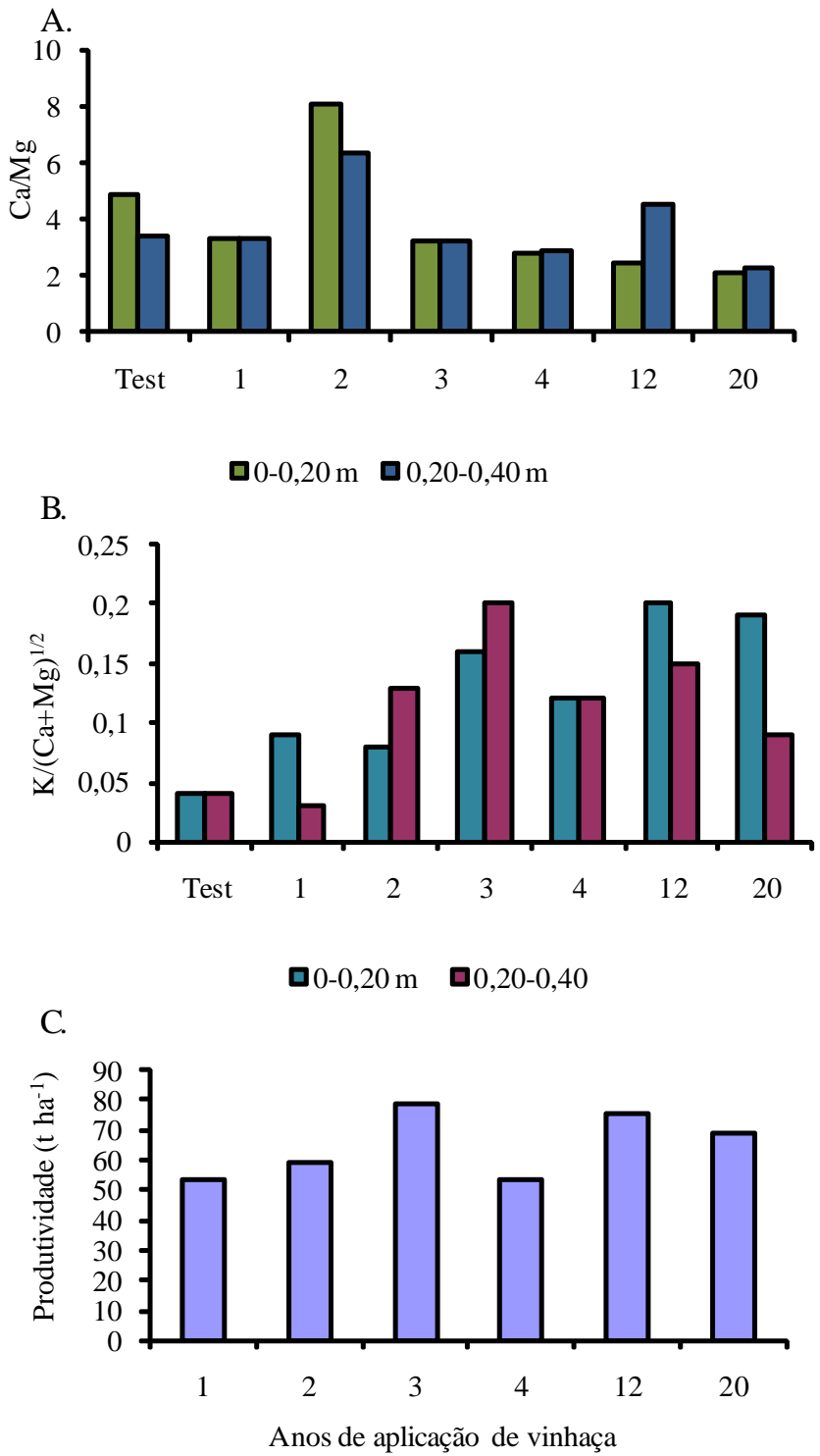

Figura 4. Relação $\mathrm{Ca} / \mathrm{Mg}(\mathrm{A}), \mathrm{K} /(\mathrm{Ca}+\mathrm{Mg})^{1 / 2}(\mathrm{~B})$ e produtividade da cana-de-açúcar (C) para as áreas estudadas

\section{ConclusõES}

1. A partir da primeira aplicação de vinhaça ocorreu aumento no teor de carbono orgânico e potássio no solo.

2. O aumento do teor de carbono orgânico influenciou positivamente a densidade, CTC e a porosidade total do solo.

3. Mais de $83 \%$ da água disponível para as plantas ficaram retidos até a tensão de $600 \mathrm{kPa}$, não se verificando uma relação entre a retenção de água no solo e os anos de aplicação de vinhaça.

4. A produtividade da cultura da cana-de-açúcar apresentou uma relação direta ao aumento da razão de adsorção de potássio no solo.

\section{LITERATURA CITADA}

Andrioli, I. Efeitos da vinhaça em algumas propriedades químicas e físicas de um Latossolo Vermelho-Escuro textura média. Piracicaba: ESALQ, 1986. 85p. Tese Doutorado
Bebé, F. V.; Rolim, M. M.; Pedrosa, E. M. R.; Silva, G B.; Oliveira, V. S. Avaliação de solo sob diferentes períodos de aplicação com vinhaça. Revista Brasileira de Engenharia Agrícola e Ambiental, v.13, n.6, p.781-187, 2009.

Boeira, R. C.; Souza, M. D. Estoques de carbono orgânico e de nitrogênio, $\mathrm{pH}$ e densidade de um Latossolo após três aplicações de lodos de esgoto. Revista Brasileira de Ciência do Solo, v.31, n.3, p.581-590. 2007.

Braida, A. J.; Reicherdt, M. J.; Veiga, M.; Reinert, J. D. Resíduos vegetais na superfície e carbono orgânico do solo e suas relações com a densidade máxima obtida no ensaio proctor. Revista Brasileira de Ciência do Solo, v.30, p.605-614, 2006.

Camargo, O. A.; Alleoni, L. R. F. Reconhecimento e medida da compactação do solo. http://www.infobibos.com/Artigos/ 2006_2/C6/Index.htm. 12 Jul. 2009.

Camargo, O. A.; Valadares, J. M. A. S.; Geraldi, R. N. Características químicas e físicas de solo que recebeu vinhaça por longo tempo. Campinas: Instituto Agronômico de Campinas. 1983. 30p. Boletim Técnico, n.76

Camilotti, F.; Andrioli, I.; Marques, O. M.; Silva, A. R.; Tasso Junior, L. C. Avaliação dos teores de metais pesados no solo e na planta de cana-de-açúcar sob adubação com lodo de esgoto e vinhaça. Journal of Biosciences, v.25, n.23, p. 23-31, 2009.

Camilotti, F.; Andrioli, I.; Marques, M. O.; Silva, A. R.; Tasso Júnior, L. C.; Nobile, F. O. Atributos físicos de um latossolo cultivado com cana-de-açúcar após aplicações de lodo de esgoto e vinhaça. Engenharia Agrícola, v.26, n.3, p.738-747, 2006.

Canellas, L. P.; Velloso, A. C. X.; Marciano, C. R.; Ramalho, J. F. G. P.; Rumjanek, V. M.; Rezende, C. E.; Santos, G. A. Propriedades químicas de um Cambissolo cultivado com cana-de-açúcar, com preservação do palhiço e adição de vinhaça por longo tempo. Revista Brasileira de Ciência do Solo, v.27, n.5, p.935-44, 2003.

Casarini, D. C. P.; Cunha, R. C. A.; Masset Filho, B. Modificação da densidade da microflora em um solo tratado com vinhaça. Revista DAE, v.45, n.142, p.316-321, 1985.

Ciotta, N. M.; Bayer, C.; Fontoura, V. M. S.; Ernani, R. P.; Albuquerque, A. J. Matéria orgânica e aumento da capacidade de troca de cátions em solo com argila de atividade baixa sob plantio direto. Ciência Rural, v.33, n.6, p.1161-1164, 2003.

Dourado Neto, D.; Nielsen, R. D.; Hopmans, W. J.; Reichardt, K.; Bacchis, S. O. Programa para modelagem de curvas de retenção de água no solo. Scientia Agricola, v.57, n.1, p.191192, 2000.

EMBRAPA - Empresa Brasileira de Pesquisa Agropecuária. Sistema brasileiro de classificação de solos. Rio de Janeiro: EMBRAPA SPI, 1999. 306p.

Glória, N.; Orlando Filho, J. Aplicação de vinhaça: Um resumo e discussões sobre o que foi pesquisado. Revista Álcool Açúcar, v.16, p. 32-39, 1983.

Marciano, R. C.; Moraes, S. O.; Oliveira , F. C.; Mattiazzo, M. E. Efeito do lodo de esgoto e do composto de lixo urbano sobre a condutividade hidráulica de um Latossolo Vermelho Amarelo saturado e não saturado. Revista Brasileira de Ciência do Solo, v.25, n.1, p.1-9, 2001.

Reichardt, K.; Timm, L. C. Solo, planta e atmosfera: conceitos, processos e aplicações. 2.ed. Barueri: Manole Editora Ltda, 2008. v.1. 480p. 
Rossetto, R.; Spironello, A.; Cantarella, H.; Quaggio J. A. Calagem para a cana-de-açúcar e sua interação com a adubação potássica. Bragantia, v.63, n.1, p.105-119, 2004.

Sambatti, J. A.; Souza Júnior, I. G.; Costa, A. C. S.; Tormena, C. A. Estimativa da acidez potencial pelo método do $\mathrm{pH}$ SMP em solos da formação Caiuá: Noroeste do estado do Paraná. Revista Brasileira de Ciência doSolo, v.27, n.2, p.751-757, 2003.

Silva, A. J. N. Alterações físicas e químicas de um Argissolo amarelo sob diferentes sistemas de uso e manejo. Revista Brasileira de Engenharia Agrícola e Ambiental, v.10, n.1, p.7683, 2006.
Silva, A, J. N.; Cabeda, V. S. M.; Lima, F. W. F. J. Efeito de sistemas de uso e manejo nas propriedades físico-hídricas de um Argissolo Amarelo de tabuleiro costeiro. Revista Brasileira de Ciência do Solo, v.29, p.833-842, 2005.

Silva, S. S.; Garcia, C. A.; Silva, C. M. O destino do bagaço da cana-se-açúcar: um estudo a partir das agroindústrias sucroalcoleiras do Paraná. Revista em Agronegócios e Meio Ambiente, v.3, n.1, p.59-76, 2010.

Vitti, G. C.; Mazza, J. A. Aspectos importantes no manejo da cana-de-açúcar. Piracicaba: FERTIZA/CEA, 1998. 3p. Folder Técnico. 